\title{
Switching on microglia with electro-conductive multi walled carbon nanotubes
}

\author{
Silvana Fiorito a, *, Julie Russier ${ }^{\mathrm{b}}$, Adele Salemme ${ }^{\mathrm{c}}$, Marzia Soligo ${ }^{\mathrm{a}}$, Luigi Manni ${ }^{\mathrm{a}}$, \\ Ewa Krasnowska ${ }^{a}$, Sylvie Bonnamy ${ }^{\mathrm{d}}$, Emmanuel Flahaut ${ }^{\mathrm{e}}$, Annalucia Serafino ${ }^{\mathrm{a}}$, \\ Giuseppina Ines Togna ${ }^{c}$, Lionel N.J.L. Marlier ${ }^{a}$, Anna Rita Togna ${ }^{c}$ \\ a Istituto di Farmacologia Traslazionale, CNR, Rome, Italy \\ ${ }^{\mathrm{b}}$ Institut de Biologie Moléculaire et Cellulaire, CNRS, Strasbourg, France \\ c Dipartimento di Fisiologia e Farmacologia, Università Sapienza, Rome, Italy \\ d ICMN, UMR 7374 CNRS, Université d'Orléans, Orléans, France \\ e CIRIMAT, Université de Toulouse, CNRS, INPT, UPS, UMR CNRS-UPS-INP N 5085, Université Toulouse 3 Paul Sabatier, Toulouse, France
}

\section{A R T I C L E I N F O}

\section{Article history:}

Received 31 March 2017

Received in revised form

14 December 2017

Accepted 17 December 2017

Available online 18 December 2017

\begin{abstract}
A B S T R A C T
We explored the mechanisms underlying microglia cell-carbon nanotube interactions in order to investigate whether electrical properties of Carbon-Nanotubes (CNTs) could affect microglia brain cells function and phenotype. We analyzed the effects induced by highly electro-conductive Multi-WalledCarbon-Nanotubes ( $\alpha$-MWCNTs), on microglia cells from rat brain cortex and compared the results with those obtained with as prepared not conductive MWCNTs (MWCNTs) and redox-active Double-WalledCarbon-Nanotubes (DWCNTs). Cell viability and CNT capacity to stimulate the release of nitric oxide (NO), pro-inflammatory (IL-1 $\beta$, TNF- $\alpha$ ) and anti-inflammatory (IL-10, TGF- $\beta 1$ ) cytokines and neurotrophic factors (mNGF) were assessed.

Electro-conductive MWCNTs, besides not being cytotoxic, were shown to stimulate, at $24 \mathrm{~h}$ cell exposure, classical "M1" microglia activation phenotype, increasing significantly the release of the main pro-inflammatory cytokines. Conversely, after $48 \mathrm{~h}$ cell exposure, they induced the transition from classical "M1" to alternative "M2" microglia phenotype, supported by anti-inflammatory cytokines and neuroprotective factor mNGF release. The analysis of cell morphology change, by tubulin and CD206 + labelling showed that M2 phenotype was much more expressed at $48 \mathrm{~h}$ in cells exposed to aMWCNTs than in untreated cells.

Our data suggest that the intrinsic electrical properties of CNTs could be exploited to modulate microglia phenotype and function stimulating microglia anti-inflammatory potential.
\end{abstract}

() 2017 Elsevier Ltd. All rights reserved.

\section{Introduction}

Beyond their unusual mechanical properties, metallic carbon nanotubes (CNTs) possess, depending on their structure, a large electrical conductivity that enables them to conduct low voltage electrical currents between electrochemical interfaces. It has been demonstrated that some of the mechanisms modulating their interaction with cell membranes reside in their electrical properties $[1,2]$.

Recent researches in nanotechnologies have increasingly

\footnotetext{
* Corresponding author

E-mail address: silvana.fiorito@ift.cnr.it (S. Fiorito).
}

focused on the exploitation of CNTs as nanotools to be applied in several areas of nerve tissue engineering to modulate neurobiological processes, such as growth and organization of neural networks, in order to accomplish nerve tissue reconstruction and repair [3]. For instance, it has been recently reported that nanotubes can sustain and promote electrical activity in networks of cultured neurons [4], that functionalized carbon nanotubes (fCNTs) induce neurites outgrowth in dorsal root ganglion neurons [5], and that CNT interfaces enhance neurite outgrowth [6].

Despite CNTs are currently investigated for their beneficial use in nervous system tissue engineering, the number of studies about the effects of CNTs on microglia cells, the resident immune cells of the brain that possess a key role in modulating both CNS injury and repair, is limited. 
Inflammatory responses characterized by pro-inflammatory molecules production, oxidative stress, free radicals production, peroxidation product accumulation and DNA damages in different cell types, and among them neural cells, exposed to CNTs have been reported, but a few data on the interactions between these carbon nanoparticles and microglia exist [7-17].

The central nervous system (CNS) is composed of a complex network of neurons and neuroglial cells. The term neuroglia covers several highly heterogeneous populations of cells that form a supporting structure for the neurons, providing them with insulation, and regulating brain homeostasis. Recently, the key role played by glia in the progression and outcome of most neurological diseases has been highlighted [18,19].

Microglia are considered as the brain's resident immune cells that, similarly to macrophages, are activated in response to inflammatory/immunological stimulations and/or neurological injuries [20]. Depending on the phenotype, microglia can produce either cytotoxic or neuro-protective effects [21]. In the mature brain, microglia typically exist in a resting state and monitor the brain environment [22]. In response to brain injury or immunological stimuli, microglia are readily activated and undergo a consistent transformation from their ramified resting state towards an amoeboid morphology [23]. Classically activated microglia called "M1" phenotype, are involved in the regulation of brain development by enforcing, through the production of proinflammatory molecules, the programmed elimination of neural cells [24]. Alternatively activated microglia called "M2" phenotype, enhance neuronal survival through the release of trophic and antiinflammatory factors and anti-inflammatory cytokines [25]. Besides, "M2" microglia facilitate neuronal repair through the guided migration of stem cells towards the site of inflammation and injury and could be involved in neurogenesis [26]. In their activated state, microglial cells react to endogenous or exogenous signals with a variety of physiological responses [27]. Recent studies have shown that, in response to certain environmental toxins, endogenous proteins and bacterial or viral signals microglia can enter in an over activated state and release neurotoxic and pro-inflammatory factors, including nitric oxide (NO) [28], inflammatory cytokines, such as interleukin-1 $\beta$ (Il-1 $\beta$ ), tumor necrosis factor- $\alpha$ (TNF- $\alpha$ ), reactive oxygen species (ROS) [29], and glutamate [30]. Microglia can also undergo the alternative $\mathrm{M} 2$ phenotype as a consequence of parasite invasion and in response to endogenous immune signals, in order to provide tissue repair and resolution of inflammation [31]. Recently, emerging lines of evidence indicate that physiological functions of microglia play a key role in the regulation of CNS activity, impact neuronal circuitry and network connectivity, and contribute to neuronal plasticity [21,28]. Thus, microglial cells can be considered as dual-functioning cells that are critical in normal as well as in diseased CNS.

Given the major importance of microglial cells in regulating brain functions and in view of the potential exploitation of carbon-based nanoparticles for neuro-regeneration and neuronal repair, we aimed to assess the potential of three different CNT types to modulate the function of microglial cells. At this purpose we challenged microglia with pristine multi-walled-carbon-nanotubes (MWCNTs), pristine annealed multi-walled-carbon-nanotubes with electro-conductive properties ( $\alpha$-MWCNTs) and doublewalled-carbon-nanotubes (DWCNTs). We first investigated the cytotoxic potential of the three CNT samples on microglia cells isolated from rat brain cortex. Then we assessed microglia phenotype changes and measured the main pro-inflammatory (TNF- $\alpha$, IL$1 \beta$ ), anti-inflammatory (IL-10, TGF- $\beta 1$ ), neuro-toxic (glutamate) and neuro-protective (mature Nerve Growth Factor) molecules secreted by microglia cells at $24 \mathrm{~h}$ and $48 \mathrm{~h}$ exposure. Cell exposure was limited to $48 \mathrm{~h}$ because a prolonged exposure, being a primary culture, could have reduced cellular vitality invalidating the results; furthermore, our aim was to explore the short term cell response to CNTs, and especially to electro-conductive $\alpha$-MWCNTs, due to our previous findings showing that CNT electrical properties affect significantly the so called "charge-sensitive" cell parameters and stimulate the cellular pro-inflammatory response in a very short time $[1,2]$. The results of the present study showed that only electro-conductive $\alpha$-MWCNT, besides not being cytotoxic, were able to stimulate, at $24 \mathrm{~h}$ cell exposure, the classical microglia activation (M1 phenotype) with production of pro-inflammatory molecules, then to induce, after $48 \mathrm{~h}$ exposure, the transition to M2 phenotype (alternative activation), with production of antiinflammatory cytokines and of the neurotrophic factor mNGF.

\section{Experimental}

\subsection{Carbon nanotube samples}

MWCNTs (CRMD, Orléans, France) were synthesized by a regular catalytic chemical vapor deposition (CCVD) technique, as described [1]. A full characterization of the two MWCNT samples was previously assessed (Supplementary Material) [1,2]. The MWCNTs were used either as prepared and purified before annealing (MWCNTs), or after purification by annealing at $2400{ }^{\circ} \mathrm{C}$ under argon atmosphere ( $\alpha$-MWCNTs). For the in vitro studies, the MWCNT samples were sterilized by heating at $180^{\circ} \mathrm{C}$, washed three times in distilled water, then re-suspended in $\mathrm{Ca}$ - and $\mathrm{Mg}$-free phosphate buffered saline (PBS) at a concentration of $1 \mathrm{mg} / \mathrm{mL}$. Dispersion was performed through a $48 \mathrm{~h}$ gentle sonication in a bath sonicator at the lowest power and the particles were analyzed and put into the cell cultures for cell treatment immediately after sonication and vortex agitation.

The electrochemical experiments performed to investigate the electrical properties of both MWCNT samples were carried out as previously described [2]. $\alpha$-MWCNTs have been shown to exhibit a much higher electrical conductivity than MWCNTs. Double-walledcarbon-nanotubes (DWCNTs), synthesized by CCVD as described earlier [32] have been shown to possess a redox peak, with E1/2 potential, at $-70 \mathrm{mV}$, attributable to metallic impurities left over from the catalyst used in the synthesis [33]. MWCNTs, $\alpha$-MWCNTs and DWCNTs characteristics are summarized in Table 1 (Supplementary Material).

\subsection{Primary rat microglial cell cultures}

All animal related procedures were carried out in accordance with the directives of the Italian and EU regulations for care and use of experimental animals (DL116/92) and approved by the Italian Ministry of Health.

Primary microglial cells were obtained from the cerebral cortex of 1- or 2-days old rats as previously described. Briefly the cortices were dissected and cells were dispersed by mechanical and enzymatic dissociation using a solution of trypsin and DNase I (Sigma Chemicals Co., St. Louis, MO, USA) diluted in $\mathrm{Ca}^{++}$-free Phosphate Buffer Solution. Cells were plated at a density of $4.4 \times 10^{4}$ cells $/ \mathrm{cm}^{2}$ in T75 flasks, in D-MEM supplemented with $10 \%$ FCS and antibiotics ( $100 \mathrm{U} / \mathrm{mL}$ of penicillin and $100 \mathrm{mg} / \mathrm{mL}$ of streptomycin, Invitrogen Corporation, Carlsbad, CA, USA). The medium was changed after $24 \mathrm{~h}$, then twice a week. After 10-14 days from dissection, microglia was detached from the astrocyte monolayer by shaking and the cells re-suspended in DMEM/F12 supplemented with 10\% FCS and antibiotics (as above) and seeded in 24 multiwell plates at a density of $5 \times 10^{5}$ cells $/ \mathrm{mL}$, and incubated at $37^{\circ} \mathrm{C}$ in a humidified atmosphere containing $5 \% \mathrm{CO}_{2}$. For confocal microscopy investigations, purified microglia was seeded on Lab-Tek ${ }^{\mathrm{TM}}$ II 8 wells Chamber 
Table 1

Characteristics of CNT samples.

\begin{tabular}{|c|c|c|}
\hline & DWCNTs $^{\mathrm{a}}$ & MWCNTs $^{b}$ \\
\hline Synthesis/production & CCVD & CCVD \\
\hline Catalyst & Co/Mo-MgO & CoMgO \\
\hline Chemical composition (wt. \%) & $\begin{array}{l}92 \% \mathrm{C} \\
(5 \% \mathrm{Co}, \mathrm{Mo})\end{array}$ & $\begin{array}{l}\text { MWCNTs (as-prepared): } \\
99 \% \text { C (Co } 0.06 \text { at\%; O } 0.5 \text { at \%) } \\
\text { a-MWCNTs (annealed at } \\
2400{ }^{\circ} \text { C): } \\
100 \% \text { C (O } 0.2 \text { at\%) }\end{array}$ \\
\hline $\begin{array}{l}\text { Number of walls/layers } \\
\text { (from HRTEM) }\end{array}$ & $80 \%$ DWNTs, $15 \%$ SWCNTs, $5 \%$ TWCNTs & 15 \\
\hline 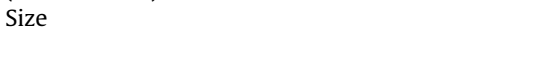 & Length: $1-10 \mu \mathrm{m}$; up to $>100 \mu \mathrm{m}$ when in bundles. Diameter $1-3 \mathrm{~nm}$ (from TEM) & $\begin{array}{l}\text { Length:. } 1-10 \mu \mathrm{m} \\
\text { Diameter: } 10-15 \mathrm{~nm} \text { (from TEM) }\end{array}$ \\
\hline Experimental Specific surface area $\left(\mathrm{m}^{2} / \mathrm{g}\right)$ (from BET) & 980 & 240 \\
\hline
\end{tabular}

CCVD: Chemical Catalytic Vapor Deposition.

a E. Flahaut, R. Bacsa, A. Peigney, Ch. Laurent. Gram-Scale CCVD Synthesis of Double-Walled Carbon Nanotubes. Chem Commun $2003 ; 12$ : $1442-1443$.

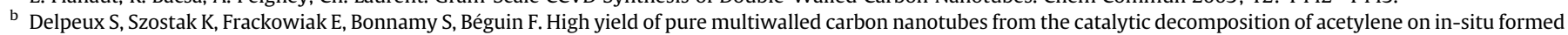
cobalt nanoparticles. J Nanosci Nanotechnol 2002; 2:481-484.

Slide (Nunc $^{\mathrm{TM}}$, Thermo Scientific, USA) at a density of $1 \times 10^{5}$ cells/mL. Purity of microglial cell populations $(>98 \%)$ was verified by staining with Iba-1 (1:1000) antibody (Wako Pure Chemical Industries Ltd., Osaka, Japan) (Fig. 1S). Cells were treated with CNT samples for $24 \mathrm{~h}$ up to $48 \mathrm{~h}$ at a concentration of $60 \mu \mathrm{g} /$ $\mathrm{mL}$. This concentration was selected, based on our previous experiments, as the lowest concentration able to affect the examined parameters, without inducing excessive cytotoxicity and in order to avoid the saturation of the response observed with higher doses.

\subsection{Cell viability}

The CNT effects on the viability and potential toxicity on the microglial cells were assessed by three experimental approaches. First of all we evaluated the effect of CNTs on the capacity of cells to adhere to the culture plate, by measuring the number of cells attached to the plate after $24 \mathrm{~h}$ and $48 \mathrm{~h}$ CNT exposure. Then, the potential toxicity of the different CNTs was investigated by cell counting using Trypan blue exclusion. For this purpose, cells were seeded and treated with CNTs $(60 \mu \mathrm{g} / \mathrm{mL})$ in 6 wells plates at a density of $10^{6}$ cells/well. The medium was collected after $24 \mathrm{~h}$ or $48 \mathrm{~h}$ and spun down to recover cells not attached to the bottom of the dish. Conversely, attached cells were mechanically dislodged with trypsin. Both cell fractions were counted using an hemocytometer. The statistical deviation was calculated from 3 dishes for each condition.

Secondly, the same experimental design was repeated, the medium was removed, cells detached with trypsin and incubated with Trypan blue. Cell viability was determined after $24 \mathrm{~h}$ and $48 \mathrm{~h}$ treatment, based on the Trypan blue exclusion method.

Finally, in order to detect the cytotoxic effect of these CNTs we evaluated their capacity to induce cell necrosis by using a cytotoxicity detection kit for lactate dehydrogenase (LDH, from Roche Diagnostics, Indianapolis, IN, USA), a classic cell death marker, whose release indicates the cellular membrane rupture. This assay was performed in a 96-well microplate, according to the manufacturer's recommendations. Briefly, $100 \%$ toxicity corresponds to the total amount of LDH cells can release after solubilization of the membrane.

\subsection{Imaging}

\subsubsection{Determination of apoptotic cells by TUNEL labelling}

Then we investigated, by TUNEL labeling, whether CNTs could induce another kind of cell death: apoptosis. Indeed, cell death can occur in various ways (necrosis, apoptosis, autophagy) and for various causes (physiological or pathological). Apoptosis is a type of programmed cell death that occurs physiologically and/or pathologically in response to different stimuli. For TUNEL labeling, microglial cells seeded onto 8-wells Lab-Tek ${ }^{\mathrm{TM}}$ were fixed after $48 \mathrm{~h}$ CNTs exposure with paraformaldehyde $4 \%$ in phosphate buffer (Sigma Chemicals Co., St. Louis, MO, USA) and then permeabilized briefly with Triton $\times 100$. Cells were then labeled with terminal deoxynucleotidyl transferase (TdT, 40 units) and $5 \mu \mathrm{M}$ Biotin in TUNEL Buffer (Roche, Basel, Switzerland) for $1 \mathrm{~h}$ at $37^{\circ} \mathrm{C}$ as previously described [34].

Positive cells were detected using Streptavidin Alexa Fluor 647 conjugate (Invitrogen Corporation, Carlsbad, CA, USA, working dilution 1:200). Positive TUNEL controls were obtained after exposure of CNT untreated microglia to DNAse (Sigma Chemicals Co., St. Louis, MO, USA) for $1 \mathrm{~h}$ at $37^{\circ} \mathrm{C}$, while negative controls, for immunofluorescent background determination, were obtained by omitting the Biotin during TUNEL labeling.

For the quantitative assessment analysis, 300 nuclei/experimental paradigm were counted on random microscope fields and results were expressed as percentage of cells exhibiting nuclear TUNEL labeling.

\subsubsection{Determination of autophagosome formation}

Furthermore, we evaluated the CNT capacity to induce the third type of cell death: autophagy, a physiological process that the cells perform, generally, in the event of nutrient deficiency. Autophagy was evaluated by analyzing the redistribution at level of cytoplasmic vacuoles of the autophagy membrane marker LC3. Cells seeded onto 8-wells Lab-Tek ${ }^{\mathrm{TM}}$ and treated with CNTs for $48 \mathrm{~h}$ were fixed and permeabilized as above, then processed for immunofluorescent staining using a primary antibody against LC3 (Abcam, working dilution 1:200 for $1 \mathrm{~h}$ at room temperature) revealed using an Alexa Fluor ${ }^{\mathbb{B}} 488$ anti-rabbit secondary antibody (Invitrogen, Thermo Fisher Scientific, working dilution 1:200 for $1 \mathrm{~h}$ at room temperature). Nuclei were counterstained with Hoechst dye.

Cells grown in serum-free medium for $24 \mathrm{~h}$ (starvation condition), were used as positive control of autophagy.

\subsubsection{Determination of cell morphology change by tubulin labeling}

To assess cell morphology changes after CNT exposure, cells were seeded, CNTs treated and processed as above, then subjected to immunofluorescent staining using a primary antibody against tubulin (Sigma Chemicals Co., St. Louis, MO, USA, working dilution $1: 2000$ for $1 \mathrm{~h}$ at room temperature) and a secondary Alexa Fluor ${ }^{\circledR}$ 488 anti-mouse antibody (Invitrogen, Thermo Fisher Scientific, working dilution 1:200 for $1 \mathrm{~h}$ at room temperature). Nuclei were 
counterstained with Hoechst dye (Sigma Chemicals Co., St. Louis, MO, USA).

\subsubsection{Determination of $M 1 / M 2$ transition}

Cells were treated with CNTs and prepared for immunofluorescence as described above. Antibodies used were:

- Mouse monoclonal anti-CD11b from Abcam, working dilution $1: 100$

- Rabbit polyclonal anti-mannose receptor (CD206) from Abcam, working dilution 1:200

- Alexa Fluor ${ }^{\circledR} 488$ anti-mouse from ThermoFisher Scientific, working dilution 1:200

- Alexa Fluor ${ }^{\circledR} 594$ anti-rabbit from ThermoFisher Scientific, working dilution 1:200

All antibodies were incubated for $1 \mathrm{~h}$ at room temperature and nuclei were counterstained with Hoechst dye.

Immuno-labeling general procedure was previously described [34]. All imaging studies were conducted using a LEICA TCS SP5 confocal microscope (Leica Instruments, Wetzlar, Germany).

For quantitative analysis, for each experimental paradigm at $24 \mathrm{~h}$ or at $48 \mathrm{~h}, 300 \mathrm{CD} 11 \mathrm{~b}$ positive cells were counted on randomly accessed confocal microscope fields and, among them, the percent of CD206 positive cells was determined. This analysis was made by two persons while blinded for the experimental conditions. Results are expressed as \% M2, CD206 positive phenotype among CD11b positive cells, \pm S.D obtained from the two independent readings.

\subsection{Western blot (WB) analyses}

\subsubsection{Analysis of inducible-NOS (i-NOS) and glutamate transporters} (GLAST and GLT-1)

Inducible-Nitric Oxide Synthase (i-NOS) expression was evaluated in microglial cells treated with MWCNTs, $\alpha$-MWCNTs or DWCNTs at $60 \mu \mathrm{g} / \mathrm{mL}$ for $24 \mathrm{~h}$; GLAST and GLT- 1 glutamate transporter expression was evaluated in microglial cells treated with DWCNTs at the same concentration.

After CNT treatment, the microglial cells were lysed in ice-cold lysis buffer (10 mM Tris- $\mathrm{HCl}, \mathrm{pH} 7.5 ; 150 \mathrm{mM} \mathrm{NaCl} ; 1 \mathrm{mM}$ EDTA; $50 \mathrm{mM}$ sodium fluoride; $1 \%$ Triton X-100; $10 \%$ glycerol), supplemented with protease and phosphatase inhibitors ( $1 \mathrm{mM}$ sodium orthovanadate, $1 \mathrm{mM}$ phenylmethanesulfonyl fluoride, $25 \mathrm{mM}$ glycerol-2-phosphate, $10 \mu \mathrm{g} / \mathrm{mL}$ aprotinin and $1 \mu \mathrm{g} / \mathrm{mL}$ leupeptin). Protein concentration of each lysate was determined by Bradford assay. Equal amounts of proteins were electrophoretically separated and transferred onto nitrocellulose membrane. After blocking of the membranes, primary antibodies for iNOS, GLAST and GLT-1 were incubated at proper dilutions (1:1000 for anti-iNOS, 1:400 for anti-GLAST and 1:500 for anti-GLT-1 all from Santa Cruz, CA, USA). After washes, the membranes were incubated with an horseradish peroxidase (HRP)-conjugated anti-rabbit secondary antibody (1:2500 from Invitrogen Corporation, Carlsbad, CA, USA) and the immunoreactivity visualized by chemiluminescence (ECL) (Bio-Rad, Hercules, CA, USA) according to manufacturer's recommendations. Scanning densitometry was performed using the Image 1.47 program and signal density was normalized to $\beta$-actin signal density. Data are presented as the mean \pm S.D.

\subsubsection{Analysis of LC3 expression and turnover}

For LC3 WB analysis, cells were processed as explained above. Lysosomal turnover of endogenous LC3-II was analyzed in all samples in absence and in presence of two lysosomal protease inhibitors, E64d $(10 \mu \mathrm{g} / \mathrm{mL})$ and Pepsatin A $(10 \mu \mathrm{g} / \mathrm{mL})$ (Applichem $\mathrm{GmbH}$, Germany). A positive control was prepared by serum starvation of the cells for $48 \mathrm{~h}$.

Values were normalized to $\beta$-actin and were reported as relative amount of LC3-I and LC3-II in presence of inhibitors (\% vs untreated control) extrapolated from two separated western blot analyses. Data are presented as the mean \pm S.D.

\subsection{Nitric oxide (NO) production}

Nitric Oxide production by microglia exposed to CNTs was assessed as NO is one of the main markers of microglia "M1" activation possessing pro-inflammatory activity, unlike that one released by vascular endothelial cells that possess vasodilatation activity. Nitrite we detected derives from the activity of iNOS.

Microglial cells were exposed for $24 \mathrm{~h}$ to $60 \mu \mathrm{g} / \mathrm{mL}$ MWCNTs, $\alpha$ MWCNTs or DWCNTs. NO production in microglial culture supernatants was evaluated by measuring nitrite, a stable end product of NO. Nitrite was determined by a colorimetric assay with Griess reagent. One-hundred microliters of culture medium was reacted with an equal volume of Griess reagent (one part of $1 \%$ sulphanilamide dissolved in $5 \% \mathrm{H}_{3} \mathrm{PO}_{4}$ and one part of $0.1 \%$ naphthylethylenediamine dissolved in distilled water) in 96-well culture plates for $10 \mathrm{~min}$ at room temperature. The absorbance was measured with a microplate reader at $545 \mathrm{~nm}$ using a calibration curve made of sodium nitrite standards $(0.7-50 \mu \mathrm{M})$.

\subsection{ELISA analyses}

\subsubsection{Cytokines release}

Cells were treated with MWCNTs, $\alpha$-MWCNTs and DWCNTs at $60 \mu \mathrm{g} / \mathrm{mL}$ for $24 \mathrm{~h}$ or $48 \mathrm{~h}$. The supernatants were then withdrawn and pro-inflammatory cytokines TNF- $\alpha$ and IL-1 $\beta$ and antiinflammatory cytokines IL- 10 and TGF- $\beta 1$ were assayed using the following commercially available kits and following the respective manufacturer's recommendations:

- TNF- $\alpha$ : ER3TNFA from Thermo Scientific

- IL-1 $\beta$ : BMS630 from Affymetrix

- TGF- $\beta 1$ : BMS623/3 from Affymetrix

- IL-10: ERIL10 from Thermo Scientific

All those kits were purchased from ThermoFisher Scientific (Waltham, MA, USA). The colorimetric reaction was measured in absorbance mode using a Victor ELISA reader (PerkinElmer, Milan, Italy).

\subsubsection{Mature nerve growth factor ( $m N G F$ ) release}

Concentration of mNGF was analyzed, in conditioned medium, using a specific ELISA developed by Soligo et al. and recently described [35]. In brief to recognize mNGF, the AF-256-NA capture antibody (R\&D System, Minneapolis, MN, USA) was coated over night at room temperature. After blocking $1 \mathrm{~h}$ at room temperature with PBS $+1 \%$ BSA, samples were incubated for $6 \mathrm{~h}$ at room temperature. The microwells were then incubated with 27/21-mNGF detection antibody (Chemicon MAB5260Z, Merck Millipore, Vimodrone, MI, Italy) dissolved in blocking buffer overnight at $4{ }^{\circ} \mathrm{C}$. HRP-conjugated anti-mouse antibody was added and incubated for $2 \mathrm{~h}$ at room temperature. To visualize antibody reactivity the chromogenic substrate 3,3',5,5'-tetramethylbenzidine (TMB, Sigma Chemicals Co., St. Louis, MO, USA) was used and color development was stopped by adding $1 \mathrm{~N} \mathrm{HCl}$. The colorimetric reaction was measured in absorbance mode at $450 \mathrm{~nm}$ using a Multiskan EX ELISA reader (ThermoFisher Scientific Laboratory Equipment, Hudson, NH, USA). 


\subsection{Extracellular and intracellular glutamate determination}

Extracellular and intracellular glutamate levels were measured using a colorimetric glutamate assay kit from Abcam (Cambridge, UK). As reported for other experiments, microglial cells were treated with DWCNTs, MWCNTs or $\alpha$-MWCNTs at $60 \mu \mathrm{g} / \mathrm{mL}$ for $24 \mathrm{~h}$. Culture medium was collected, cells were washed with PBS and then lysed with $100 \mu \mathrm{l}$ of ice cold lysis buffer $(10 \mathrm{mmol} / \mathrm{L}$ Tris- $\mathrm{HCl}$ $\mathrm{pH} 7.5,150 \mathrm{mmol} / \mathrm{L} \mathrm{NaCl}, 1 \mathrm{mmol} / \mathrm{L}$ EDTA, $50 \mathrm{mmol} / \mathrm{L}$ sodium fluoride, $1 \%$ Triton $\mathrm{X}-100,10 \%$ glycerol). Glutamate concentrations in culture medium and in cell lysates were determined according to the manufacturer's recommendations. The absorbance was measured with a microplate reader at $450 \mathrm{~nm}$ using a calibration curve of L-glutamate $(0-10 \mathrm{nmol})$.

\subsection{Statistical analysis}

All analyses were performed in at least three independent experiments. Data were reported as mean \pm SD. Statistical analysis was performed using GraphPad Prism Software v.6.00 (GraphPad, San Diego, California). Significance between the groups was determined using one-way and two-way analysis of variance (ANOVA) followed by post hoc Bonferroni's multiple comparison test. Values of $p<.05$ were considered statistically significant.

\section{Results}

\subsection{Effects of CNTs on cell attachment and cell viability}

Cell attachment and cell viability in presence of CNTs, assessed at 24 and $48 \mathrm{~h}$, are summarized in Fig. 1. At $24 \mathrm{~h}$, MWCNTs significantly reduced the number of cells attached to the plate and, conversely, increased the number of not attached cells (Fig. 1a).
Indeed, about $35 \%$ of cells exposed to MWCNTs were found not attached compared to about $15 \%$ for cells exposed to $\alpha$-MWCNTs or about $17 \%$ for DWCNTs and about 5\% in control, untreated cells.

At $48 \mathrm{~h}$, the data for MWCNTs were almost similar for attached cells but no statistically significant difference versus control cells was observed for not attached cells. $\alpha$-MWCNTs and DWCNTs treated cultures showed results similar to control for attached cells, but the number of not attached cells was significantly increased (Fig. 1b).

Trypan blue exclusion based cell counting (Fig. 1c) showed at 24 and $48 \mathrm{~h}$ about $90 \%$ of living cells in controls $(94.21 \%$ and $90.00 \%$ respectively). $\alpha$-MWCNTs and DWCNTs barely reduced cell viability: $85.00 \%$ and $80.86 \%$ at 24 and 48 h respectively for $\alpha$ MWCNTs and $82.35 \%$ and $78.74 \%$ at 24 and 48 h respectively for DWCNT. On the contrary only MWCNTs significantly decreased cell viability as early as after $24 \mathrm{~h}$ and up to $48 \mathrm{~h}$ (64.88\% at $24 \mathrm{~h} ; 64.27 \%$ at $48 \mathrm{~h} ; \mathrm{p}<.01$ vs CTRL).

Measurement of LDH release in the culture media after $24 \mathrm{~h}$ and $48 \mathrm{~h}$ exposure to MWCNTs, $\alpha$-MWCNTs and DWCNTs, showed no significant variation with respect to control untreated cells (Fig. 1d).

\subsection{Apoptosis and autophagy}

To verify whether CNTs induced programmed cells death, we analyzed apoptosis and autophagy by confocal microscopy. The assessment of apoptosis induction was evaluated by TUNEL labeling after $48 \mathrm{~h}$ exposure, a time usually necessary but sufficient to see DNA nuclear breakdown. Positive control was obtained after DNAse treatment of the cells for $1 \mathrm{~h}$ prior to TUNEL labeling. Apoptotic cells were almost absent in cultures challenged with $\alpha$-MWCNTs as it was in control untreated cells. Conversely, a significantly increased but limited number of cells, barely superior to that observed in control untreated cultures was observed, as illustrated in Fig. 2a

\section{a: Attachment}

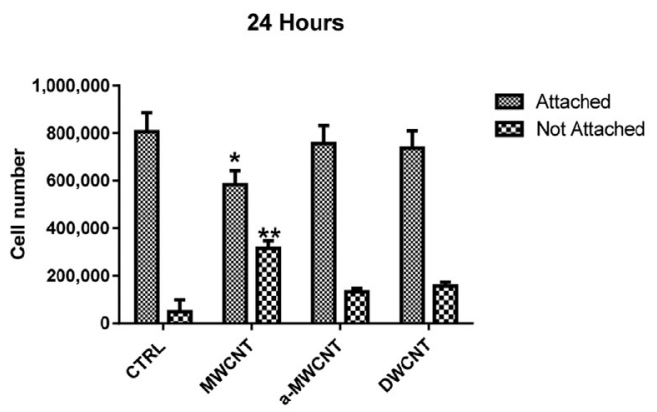

c: Viability

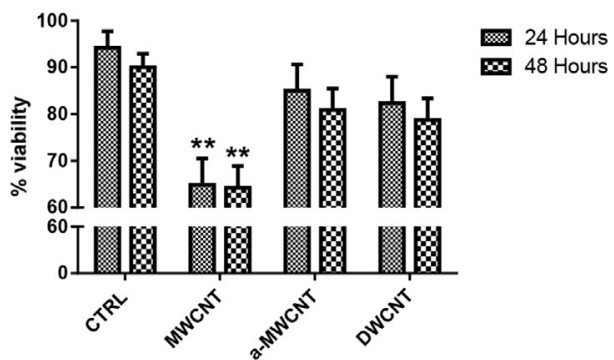

\section{b: Attachment}

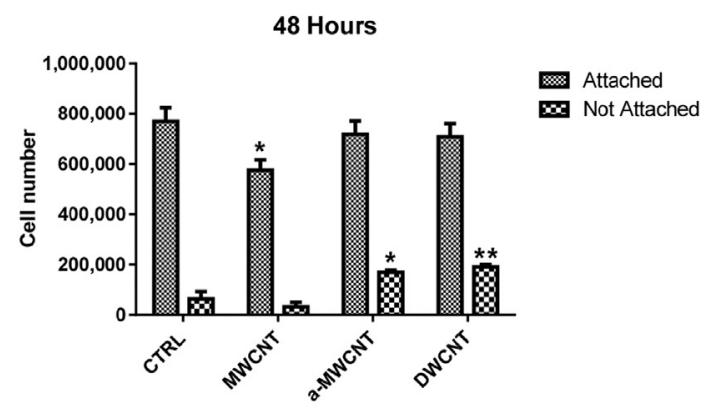

\section{d: LDH}

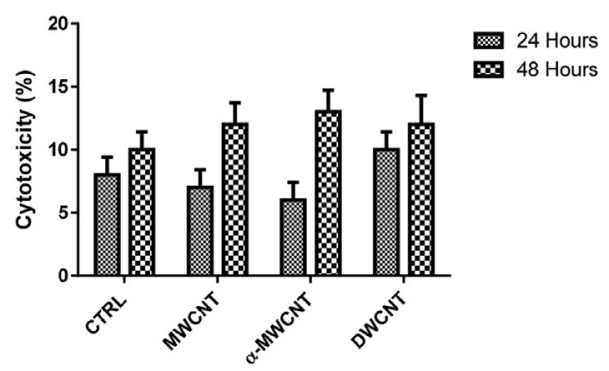

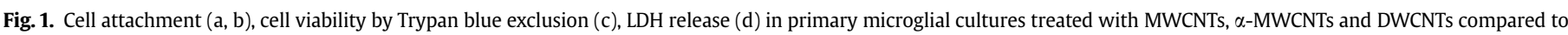
untreated control cultures after 24 and 48 h treatment. ( ${ }^{*}$ and ${ }^{* *}$ indicate $\mathrm{p}<.05$ and $\mathrm{p}<.01$ vs respective CTRL). 
Positive CTRL

b
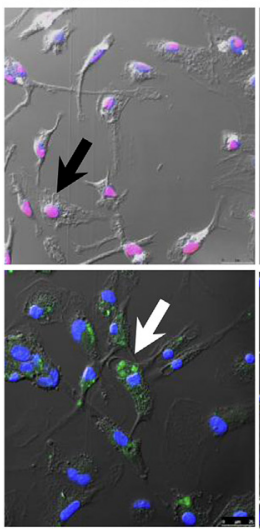

CTRL
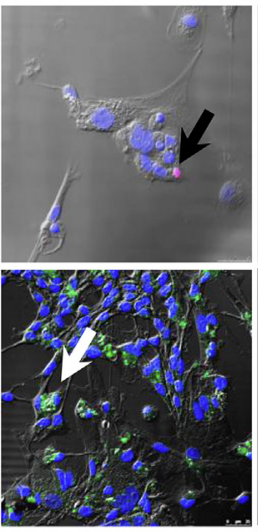

MWCNTs

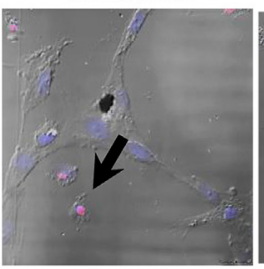

$\alpha$-MWCNTs
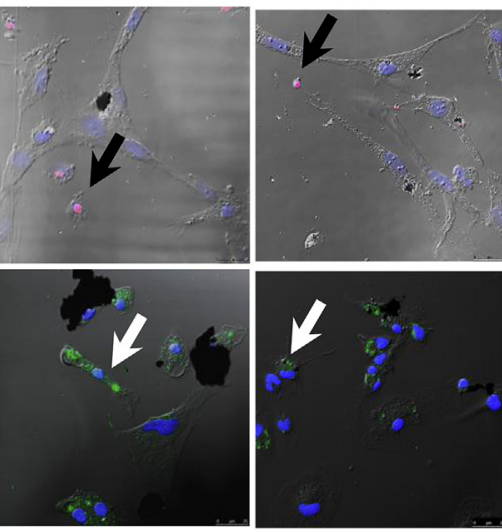

DWCNTS
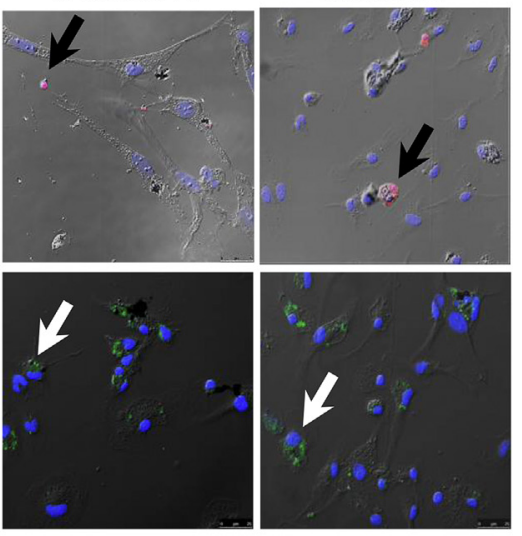

c

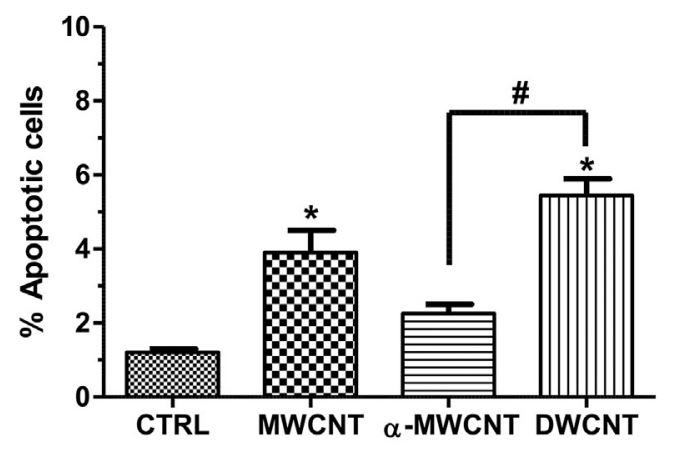

d

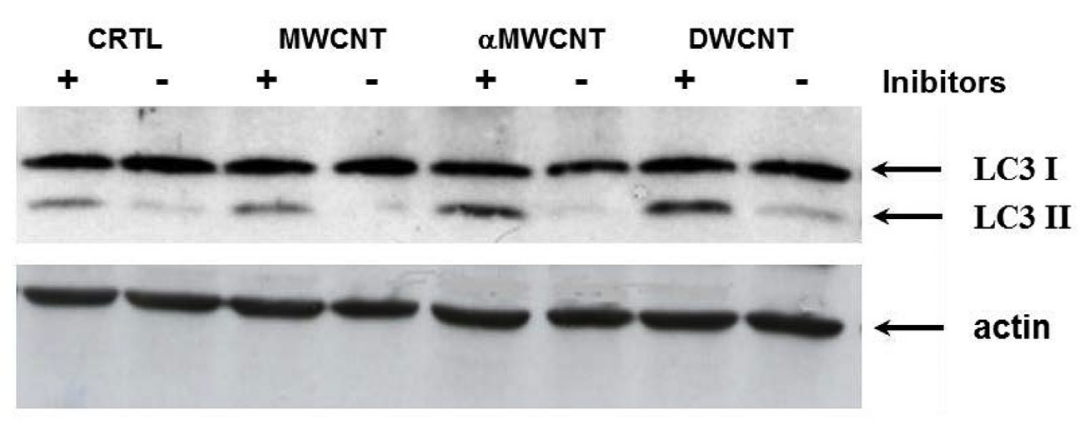

e

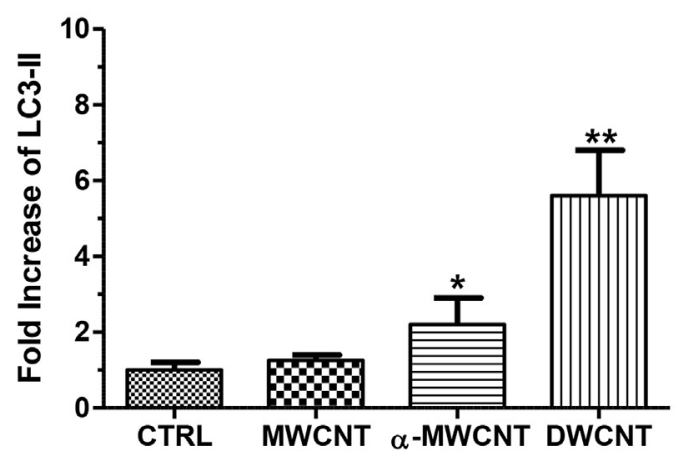

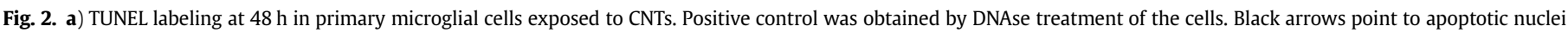

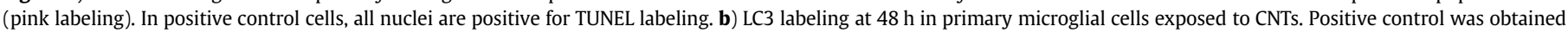

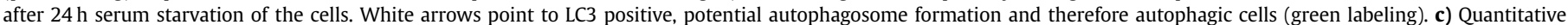


and quantified in Fig. 2c, when cells were exposed to MWCNTs and DWCNTs. Moreover, in order to rule out another possible cause of cell death, we performed a confocal microscopy analysis of LC3 labeling for the assessment of autophagy (Fig. 2b). To this purpose, control untreated cells, $24 \mathrm{~h}$ serum starved positive control cells and CNT exposed cells were labeled at $48 \mathrm{~h}$. Confocal microscopic analysis evidenced the presence of cells positive for the autophagosome marker LC3 and therefore potentially undergoing autophagy, in the cultures exposed to $\alpha$-MWCNTs and DWCNTs. To further document such a tendency, we performed a LC3 Western blot analysis of the cells with or without lysosomal protease inhibitors (LPI) pre-treatment; LPI pretreatment enhanced LC3 labeling in cells undergoing autophagy (Fig. $2 \mathrm{~d}$ and e). This approach allowed us to confirm that some cells underwent autophagy in a significant way when treated with DWCNTs, but also, to a minor extent, when treated with $\alpha$-MWCNTs. Quantitative analysis of cells undergoing apoptosis (Fig. 2c) showed that the number of apoptotic cells exposed to MWCNTs and DWCNTs was significantly higher than control and that the number of cells exposed to DWCNTs was significantly higher than that one of cells exposed to $\alpha$-MWCNTs. Quantitative analysis of cells undergoing autophagy (Fig. 2e) showed a significant increase vs control of autophagic cells in cells exposed to DWCNTs ( $\mathrm{p}<0.01)$ and to $\alpha$-MWCNTs $(\mathrm{p}<0.05)$.

3.3. Nitric oxide (NO) production and inducible nitric oxide synthase (iNOS) expression

NO production by microglial cell exposed to MWCNTs, $\alpha$ MWCNTs or DWCNTs for $24 \mathrm{~h}$ is illustrated in Fig. 3a. NO production was highly significantly $(\mathrm{p}<.01)$ induced in $\alpha$-MWCNT treated cell culture: $15.96 \mu \mathrm{M}$ for $\alpha$-MWCNTs $v s 7.82 \mu \mathrm{M}$ for controls corresponding to a two-fold increase in nitrite release $(\mathrm{p}<.01)$. MWCNT treatment also resulted in a significant NO production $(\mathrm{p}<.05)$, but to a minor extent as compared with $\alpha$-MWCNT: 1.6 fold increase (Fig. 3a).

To further investigate NO production, we analyzed inducibleNOS (iNOS) expression, by Western blot analysis, in microglial cells treated with MWCNTs, $\alpha$-MWCNTs and DWCNTs for $24 \mathrm{~h}$. Results reported in Fig. 3b, demonstrated that iNOS was significantly over expressed ( 2.67 fold increase vs untreated control) only in $\alpha$-MWCNT treated cell cultures (Fig. $3 \mathrm{~b}$ and $\mathrm{c}$ ).

\subsection{Effects of CNTs on cytokines release}

The release of the pro-inflammatory cytokines TNF- $\alpha$ and IL- $\beta$, as well as of the anti-inflammatory cytokines IL-10 and TGF- $\beta 1$ from cells exposed to the different CNT samples is shown in Fig. 4.

A significant $(\mathrm{p}<.01)$ increase in the pro-inflammatory cytokines release was detected when cells were exposed to MWCNTs or to $\alpha$-MWCNTs for $24 \mathrm{~h}$; DWCNTs did not increased proinflammatory cytokines release at $24 \mathrm{~h}$.

After $48 \mathrm{~h}$ exposure, even though a significantly reduced amount of the pro-inflammatory cytokines was observed in the supernatants of cell cultures exposed to $\alpha$-MWCNTs, the cytokine level was still significantly augmented when compared to controls also in cells exposed to MWCNTs. Conversely, the antiinflammatory cytokine release, while not increased at $24 \mathrm{~h}$ exposure in any of the CNT exposure conditions, was significantly increased in the supernatants of the cell cultures at $48 \mathrm{~h}$ exposure for $\alpha$-MWCNTs and DWCNTs.
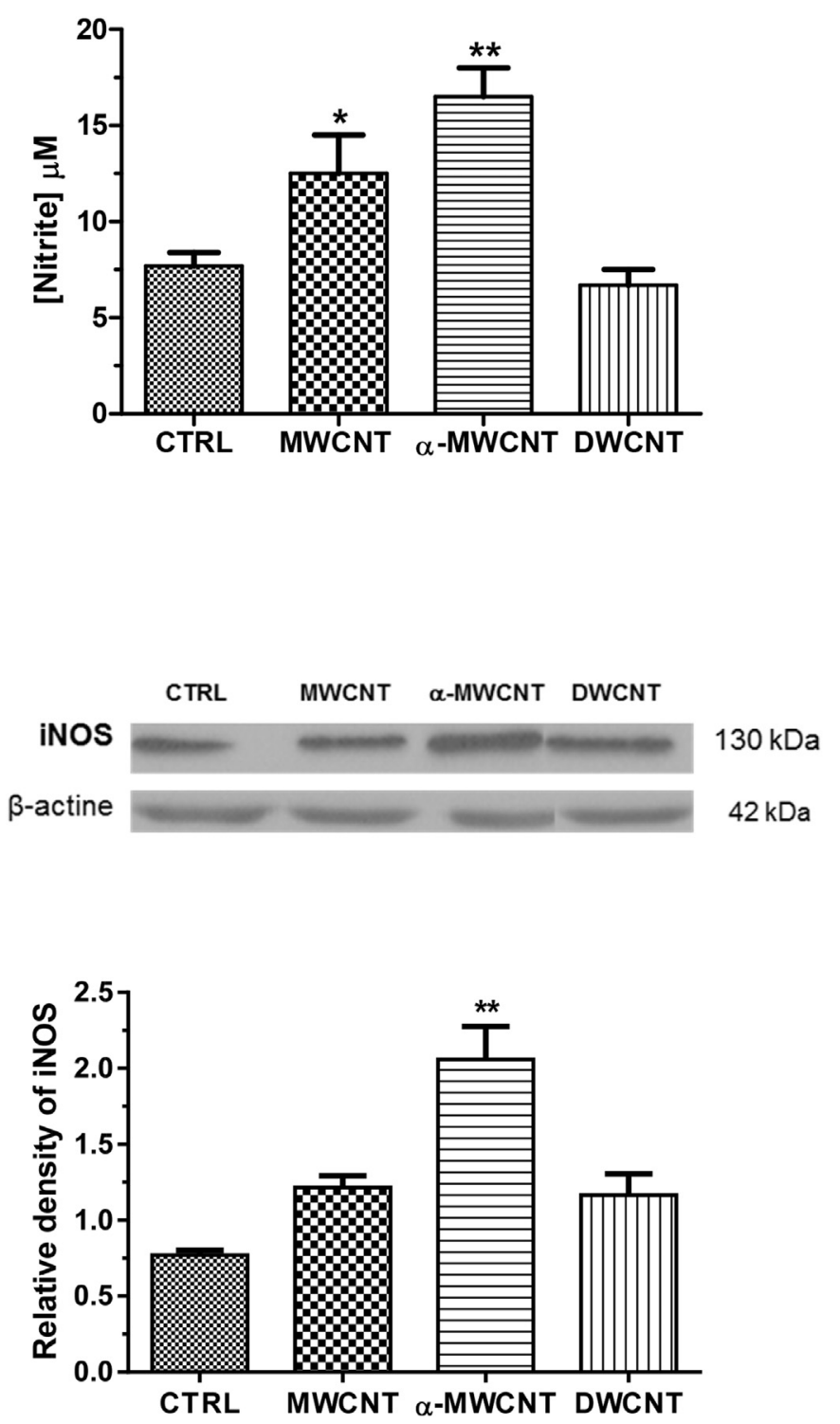

Fig. 3. a) NO production in primary microglial cultures treated with MWCNTs, aMWCNTs and DWCNTs compared to untreated control cultures after $24 \mathrm{~h}$ treatment (* $\mathrm{p}<.05$ and ${ }^{* *} \mathrm{p}<.01$ vs CTRL). b, c) Western blot analysis and densitometric analysis of iNOS expression in primary microglial cultures treated with MWCNTs, $\alpha$-MWCNTs and DWCNTs compared to untreated control cultures after 24 h treatment $\left({ }^{* *} \mathrm{p}<.01 \mathrm{vs}\right.$ CTRL).

\subsection{Effects of CNTs on mature nerve growth factor ( $m N G F$ ) release}

The 118-120 amino acid-long C-terminal peptide produced by the proteolytic cleavage of the precursor proNGF, is the mature and neurotrophic form of the NGF. The analysis of mNGF production by primary culture microglial cells exposed to CNTs at $60 \mu \mathrm{g} / \mathrm{mL}$ concentration showed that only $\alpha$-MWCNTs were able to induce the release of this neurotrophic factor starting at $24 \mathrm{~h}$ and dramatically increasing after $48 \mathrm{~h}$ exposure (Fig. 5).

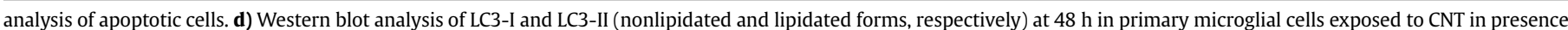
$(+)$ or absence $(-)$ of lysosomal protease inhibitors (LPI). e) Quantitative analysis of LC3-II expression.

( ${ }^{*} \mathrm{p}<.05$ vs CTRL; ${ }^{* *} \mathrm{p}<.01$ vs CTRL; \# $\mathrm{p}<.05$ vs trated). (A colour version of this figure can be viewed online.) 

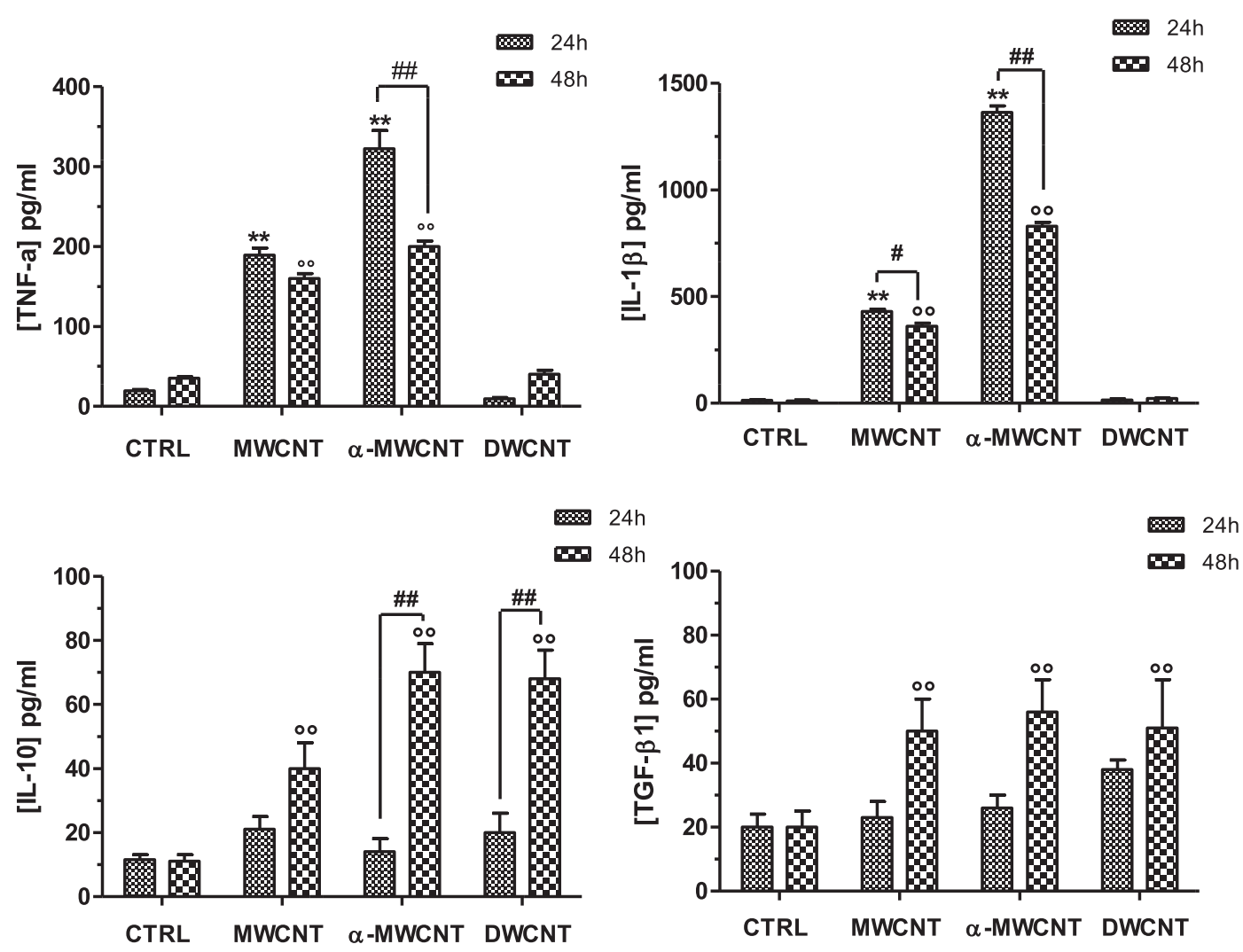

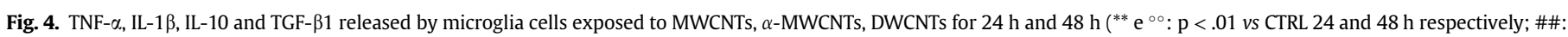
$\mathrm{p}<.01$ vs treated).

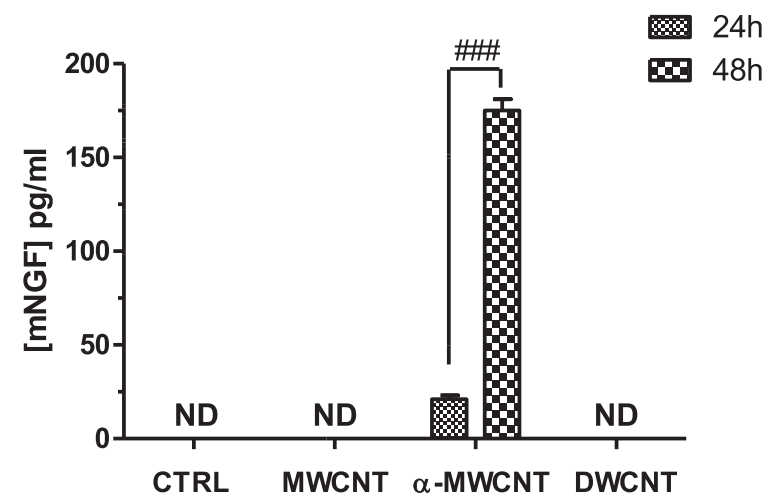

Fig. 5. mNGF released by microglia cells exposed to MWCNTs, $\alpha$-MWCNTs, DWCNTs for $24 \mathrm{~h}$ or $48 \mathrm{~h}$ (\#\#\#: $\mathrm{p}<.00124 \mathrm{~h}$ treated vs $48 \mathrm{~h}$ treated).

\subsection{Effects of CNTs on extracellular glutamate release and intracellular glutamate}

Glutammate is a neurotoxic molecule produced by microglia and released extracellularly when these cells are activated by aggressive stimuli. It is re-up-taken inside the cell as soon as its toxic action is no more required. This is why it is assessed only at $24 \mathrm{~h}$ exposure. Extracellular and intracellular glutamate levels measured in microglial cell cultures treated with $60 \mu \mathrm{g} / \mathrm{mL}$ DWCNTs, MWCNTs or $a$-MWCNTs for $24 \mathrm{~h}$ are illustrated in Fig. $6 \mathrm{a}$. The extracellular glutamate concentration measured in the medium significantly increased after $24 \mathrm{~h}$ of treatment with $a$ MWCNTs and DWCNTs, while no effect was observed with MWCNTs. Conversely, only microglia exposed to DWCNTs showed a

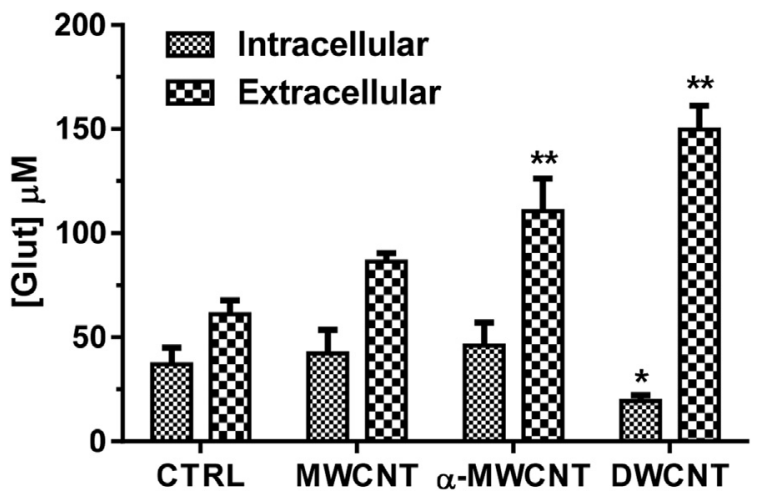

Fig. 6. Extracellular and intracellular glutamate levels measured in microglial cell cultures treated with $60 \mu \mathrm{g} / \mathrm{mL}$ DWCNTs, MWCNTs, $a$-MWCNTs and DWCNTs for $24 \mathrm{~h}$ (* and ${ }^{* *}$ indicate $\mathrm{p}<.05$ and $\mathrm{p}<.01$ vs CTRL).

significant reduction of the intracellular glutamate concentration. No effects on microglia glutamate intracellular level was noticed when the cells were challenged both with a-MWCNTs and MWCNTs (Fig. 6).

\subsection{Effects of DWCNTs on glutamate transporters GLT-1 and GLAST}

To further investigate why only cells exposed to DWCNTs showed reduced intracellular glutamate levels, we investigated by Western blot analysis the GLAST and GLT-1 glutamate transporters. GLAST and GLT-1 transporters have the function to transport glutamate from outside to inside the cell compartments, and not vice versa [36]. Their function is affected by the action of biological 
oxidants. The expression of both GLAST and GLT-1 (Fig. 7) was significantly reduced in microglia treated with DWCNTs at $60 \mu \mathrm{g} /$ $\mathrm{mL}$ for $24 \mathrm{~h}(\mathrm{p}<.01$ versus control), likely due the previously demonstrated oxidant capacity of DWCNTs [33].

\subsection{Morphological changes after CNTs exposure}

We analyzed microglial cell morphology by confocal microscopy after immunolabeling for tubulin network (Fig. 8a). In control cultures, where cells are not exposed to CNTs, both bipolar/rod-shaped microglial cells and amoeboid microglial cells could be observed both at $24 \mathrm{~h}$ and $48 \mathrm{~h}$. When exposed to MWCNTs, microglial cells tended towards the amoeboid shape, as opposed to cells exposed to $a$-MWCNTs, as most of them were found to be bipolar/rod-shaped.

DWCNT exposure conducted to an intermediate phenotype where both bipolar/rod-shaped and amoeboid cells could be observed. These morphological changes occurred already after $24 \mathrm{~h}$ and remained unchanged after $48 \mathrm{~h}$ exposure.

\subsection{Determination of M1/M2 transition}

Because of the observed results on the cytokine release showing a transition, at $48 \mathrm{~h}$, from the pro-inflammatory "M1" to the antiinflammatory "M2" phenotype in cells exposed to CNTs, we aimed to verify whether a morphological change of the cell shape was also detectable. In this set of experiments, first of all cells were labeled for CD11b (Fig. 8b, green), the classical microglial marker [37] and then for CD206 (Fig. 8b, red), the mannose receptor, a classical M2 marker. While control and treated cells were all CD11b positive, demonstrating that all cells present in the cultures were microglial cells, the $\mathrm{CD}_{206}{ }^{+} \mathrm{M} 2$ phenotype was highly significantly expressed at $48 \mathrm{~h}$ in cells exposed to $a$-MWCNTs and, even though at a minor extent, in DWCNTs. MWCNTs did not significantly differ from controls (Fig. 8c). Besides, always after $48 \mathrm{~h}$ exposure, the rodshaped morphology, already observed with tubulin labeling, was much more evident in cells exposed to $a$-MWCNTs and DWCNTs, as opposed to MWCNTs exposed cells.

\section{Discussion}

Microglia cells from rat brain cortex were challenged with pristine annealed MWCNTs ( $a$-MWCNTs) with electro-conductive properties, in order to investigate whether intrinsic electrical properties of engineered carbon-based nanoparticles could impact and/or modulate the function of these cells. As controls we used two CNT samples: pristine not annealed MWCNTs (MWCNTs), and redox-active DWCNTs (DWCNTs) [1,2,33]. Electro-conductive $a$ MWCNTs were observed not to be cytotoxic, not inducing cell necrosis or apoptosis but only decreasing cell viability in a small number of cells and inducing a slight increase of autophagic cells. Conversely, MWCNTs significantly decreased cell viability as early as after $24 \mathrm{~h}$ and up to $48 \mathrm{~h}$ and induced an increased, even though limited, number of apoptotic cells. DWCNTs barely reduced cell viability but significantly increased the number of autophagic cells.These findings are consistent with our previous results, obtained in human macrophage cells, whose viability was not significantly affected after $24 \mathrm{~h}$ exposure to $a$-MWCNTs, while exposure to MWCNTs resulted slightly more cytotoxic towards these cells [1]. The higher cytotoxic potential of pristine MWCNTs, not purified by annealing, as compared to $a$-MWCNTs, can be ascribed to their higher biological reactivity due to the presence of surface chemical functionalities that make them more reactive with the chemical species present in the biological environment and the cell components. The highly significant increase in autophagy induced by DWCNTs is also consistent with our previous results, showing an increase of autophagic cells in rat colon carcinoma cells, probably due to the redox activity of these CNTs [33]. The slight increase in the number of autophagic cells induced by $a$-MWCNTs, even though at a lower extent than that one induced by DWCNTs, could be considered a consequence of the highly stimulating activity of these CNTs on microglia that eliminate, through a physiological process, stressed cells.

Data on the neuro-toxicological profile of CNTs are limited and inconsistent [9]. In a study assessing the impact of CNTs on primary mixed neuro-glial cell cultures of the peripheral and central nervous system, an higher cytotoxicity on glial cells than on neurons has been reported [17]. The toxicity of Pluronic F127-coated MWCNTs against neuroblastoma cells was shown to be dependent on the concentration, incubation time, material purity and the presence of carboxyl groups on the acid-treated CNT surface [12]. MWCNTs with high iron catalyst impurity content were demonstrated to alter cell viability of pheochromocytoma cells [13]. More recently it has been demonstrated that functionalized MWCNTs, were not toxic towards microglial cells originating from frontal cortex but only to microglia from striatum. The authors hypothesized that the brain region-specific sensitivity was related to the higher number of microglial cells in this brain area [11]. Our data, showing that electro-conductive $a$-MWCNTs were not cytotoxic and did not affect brain cortex microglia viability, are in agreement with the above mentioned study. On the contrary, and unlike what
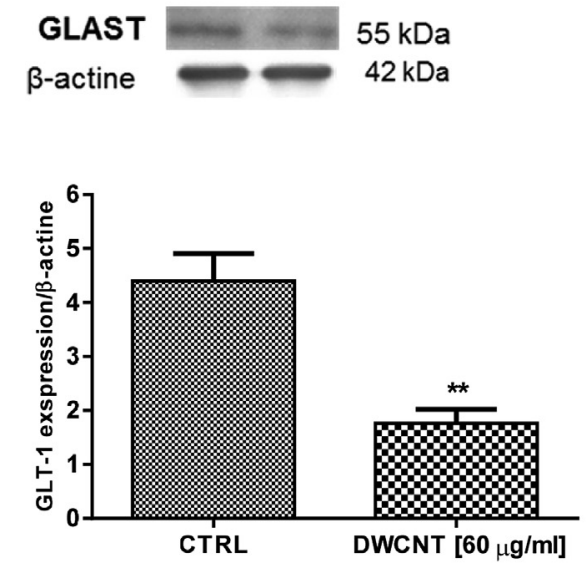
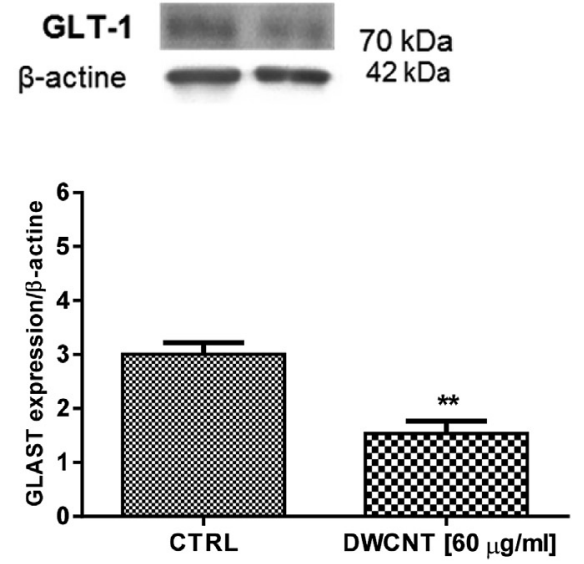

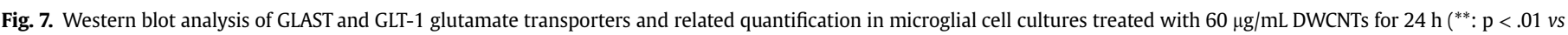
CTRL). 


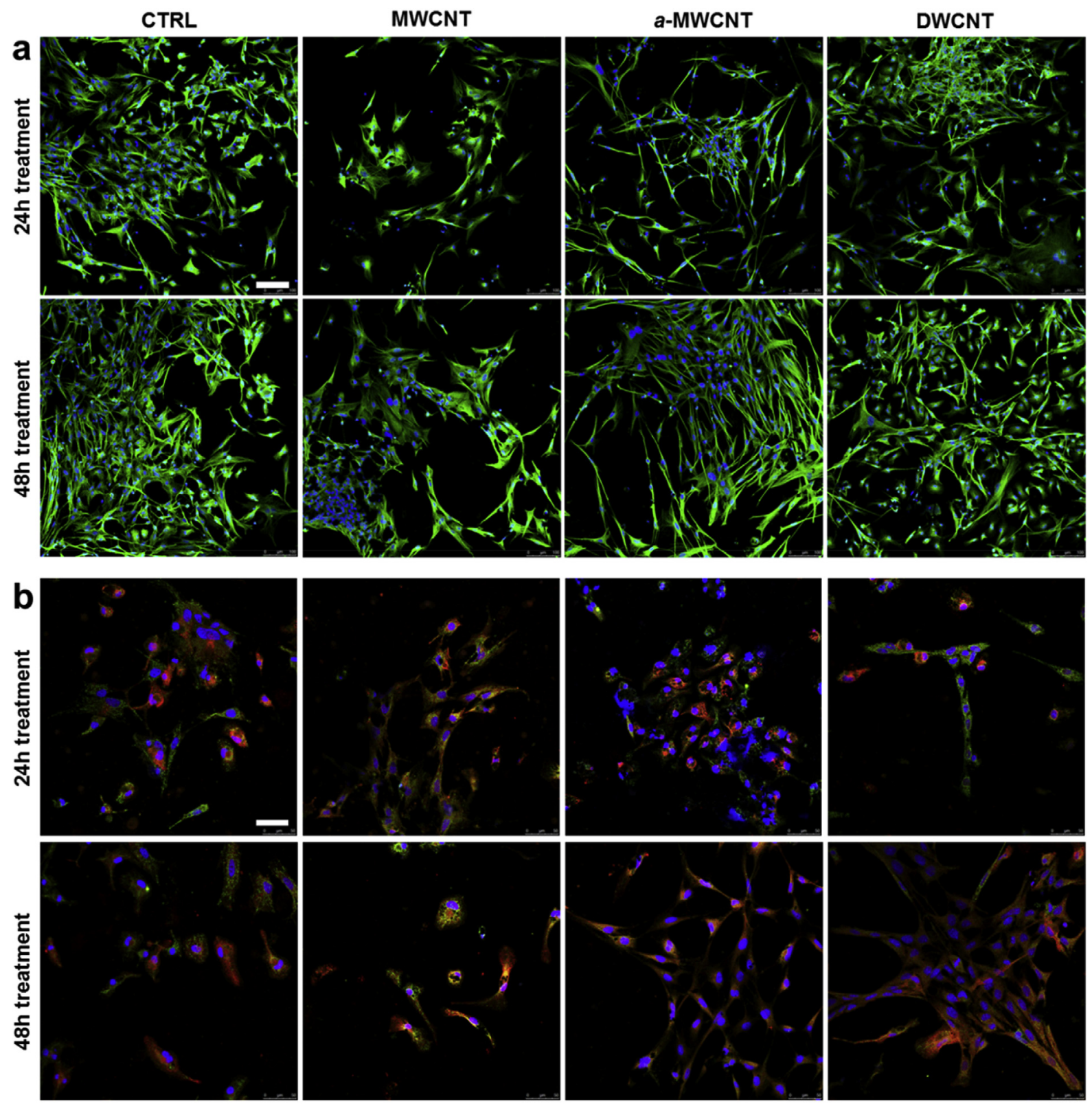

C

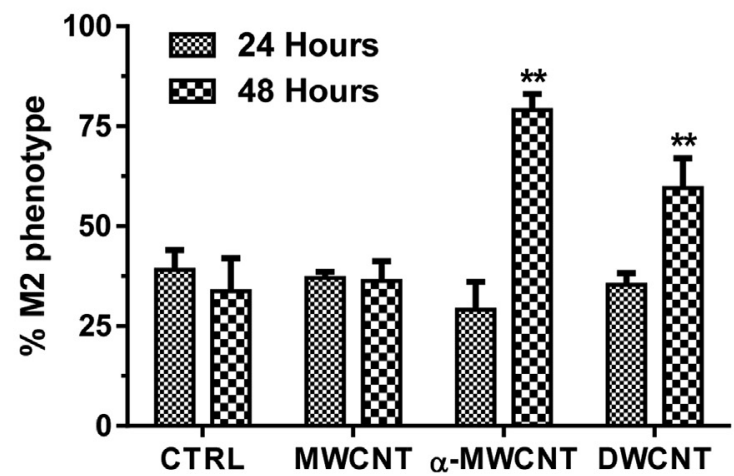

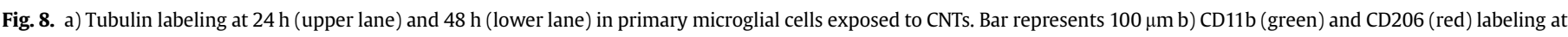

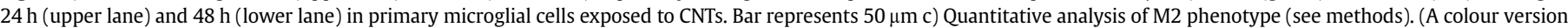
of this figure can be viewed online.) 
observed by Bussy and co-workers, our MWCNTs significantly decreased brain cortex microglia viability. This could be attributed to the high biological reactivity of these CNTs due to the high number of reactive chemical sites on their surface. Conversely, the above mentioned study was performed with functionalized MWCNTs with different surface properties than our pristine MWCNTs. So, our findings strengthen once more the assumption that CNT cytotoxicity depends equally on the peculiar characteristics (electrical properties, length, diameter, state of aggregation, grade of dispersion, functionalization, etc.) of the CNT sample tested and on the cell type used, its sensitivity, phenotype and function.

Finally, in order to further evaluate the neurotoxic activity of our CNTs, we investigated the effects of CNT exposure on extracellular/ intracellular glutamate content, a molecule secreted by activated microglia that induces neuronal toxicity. Only $a$-MWCNTs and DWCNTs induced a significant increase in extracellular glutamate level. Conversely, only microglia exposed to DWCNTs showed a significant decrease in intracellular glutamate levels, and a concomitant reduced expression of GLAST and GLT-1 glutamate transporters. Several studies have demonstrated that activated microglia release glutamate in quantities sufficient enough to induce neuronal death via over-activation of ionotropic glutamate receptors [38,39]. Excessive extracellular glutamate levels are rapidly removed from the extracellular fluid surrounding its receptors by cellular re-uptake [40]. This is accomplished by GLAST and GLT-1 glutamate transporters in the plasma membranes of both astrocytes and neurones [41]. GLAST and GLT-1 number and function is affected by the action of biological oxidants resulting in reduced glutamate intracellular re-uptake [42]. Thus, it is likely that the observed decrease in intracellular glutamate in microglia exposed to redox-active DWCNTs was due to the oxidant capacity of these CNTs. On the contrary, the normal intracellular glutamate level detected in cells exposed to $\alpha$-MWCNTs and MWCNTs could be explained by the fast intracellular re-uptake of glutamate made possible by the functioning GLAST and GLT-1 glutamate transporters. Conflicting results have been reported on the proinflammatory effects of CNTs on microglia cells. Pristine MWCNTs have been shown to be internalized by these cells, to severely impact cell migration and phagocytic capacity and to induce cell death by apoptosis [8]; non-functionalized pristine MWCNTs were shown to be up-taken by microglia without being cytotoxic [16]. Different types of chemically functionalized MWCNTs were reported to be up-taken by microglia and to induce NO release from these cells [11]. We showed that electro-conductive $a$-MWCNTs, and at a minor extent MWCNTs, possess a significantly high proinflammatory activity increasing the release of nitrites, inducible nitric oxide synthase (iNOS) and of the main pro-inflammatory cytokines (IL-1 $\beta$, TNF- $\alpha$ ) after $24 \mathrm{~h}$ exposure. This activity was shown to significantly decrease at $48 \mathrm{~h}$ while a shift to a significant increase of anti-inflammatory cytokines (IL-10 and TGF- $\beta 1$ ) occurred at that time, especially in cells exposed to $\alpha$-MWCNTs. DWCNTs did not increase pro-inflammatory cytokine levels at $24 \mathrm{~h}$ but induced a significant increase of anti-inflammatory cytokines at $48 \mathrm{~h}$. In addition, the neurotrophic factor mNGF was shown to be abundantly released only when microglia was exposed to $a$ MWCNTs after $48 \mathrm{~h}$ exposure. The neurotrophin nerve growth factor (NGF) is a well known regulator of differentiation, plasticity, and phenotype of sensory and sympathetic neurons during the entire lifespan [43]. Based on recent studies, NGF seems to modulate inflammatory cytokine production by exerting an antiinflammatory effect, mediated through its receptor TrkA, reducing inflammatory cytokine production (IL-1b, TNF-a, IL-6, and IL-8) while inducing the release of anti-inflammatory mediators (IL-10 and IL-1 receptor antagonist) [44]. Thus, $a$-MWCNTs were able to significantly stimulate pro-inflammatory activity in microglia at $24 \mathrm{~h}$. Then, the pro-inflammatory cytokines induced the release of high levels of mNGF that in turn significantly down-regulated proinflammatory cytokine release increasing at the same time antiinflammatory activity at $48 \mathrm{~h}$ in these cells.

Although cell exposure was not prolonged beyond $48 \mathrm{~h}$, to prevent too long exposure from damaging cells and altering the results, we were able to observe in this short time frame that $a$ MWCNTs changed microglia phenotype from "M1"to "M2" phenotype, not being cytotoxic.

The study of cell morphology, with immune-labeling of the tubulin network, and of the cell phenotype after immune-labeling with CD11b, the classical microglial marker and CD206, the classical M2 marker [21,37], confirmed that all the cells were CD11b positive microglial cells and that the CD206-positive "M2" phenotype was particularly expressed after $48 \mathrm{~h}$ in cells exposed to electroconductive $a$-MWCNTs. The morphology of microglia exposed to MWCNTs, showed a tendency towards the amoeboid shape, as opposed to cells exposed to a-MWCNTs, as most of them were found to be bipolar/rod-shaped. DWCNT exposure brought to an intermediate morphological pattern where both bipolar/rodshaped and amoeboid cells could be observed. These morphological changes occurred already after $24 \mathrm{~h}$ and remained unchanged after $48 \mathrm{~h}$ exposure. The morphological changes observed in microglia are the expression of their functional activities [45]. Recently, it has been shown that another microglia morphological feature exists: bipolar/rod-shaped microglia, which transiently form trains of cells aligned end-to-end close to a damaged brain site [45-51]. Recently, it has been shown the potential neuro-protective role of bipolar/rod-shaped microglia. Indeed, the spatial arrangement of bipolar/rod-shaped microglia seems to play a role in the reorganization and remodeling of neuronal circuitry following CNS injuries [52]. Our findings, showing the transition towards bipolar/ rod-shaped microglia after $a$-MWCNT cell exposure, rather than a switch towards the amoeboid shape, as observed after MWCNTs exposure, and the induction of the release of anti-inflammatory cytokines and neurotrophic factors after $48 \mathrm{~h}$ exposure, seem extremely important to support the capacity of electro-conductive $a$-MWCNTs to modulate brain cells behavior and functions towards neuroprotective effects. These findings show that a transition between the two activation states can occur when stimulating microglia with $a$-MWCNTs, solid-state nanomaterials with pronounced electrical properties, and that the anti-inflammatory state starts later than the pro-inflammatory one.

So far, to our knowledge, there are no data in the literature about the capacity of CNTs to initially activate microglia towards proinflammatory activity and later to stimulate the release of the neurotrophic factor mNGF leading to the anti-inflammatory capacity of these cells, thus changing cell phenotype and function. It is noteworthy that for the first time it is shown the role played by electro-conductive CNTs in modulating brain cells behavior. Our previous studies highlighted the existence of electro-chemical interactions taking place between cell membranes and electroconductive MWCNTs.We demonstrated the ability of elettroconductive $a$-MWCNTs to significantly affect, in a very short time, some cell functions strictly dependent on electro-chemical mechanisms (the mitochondrial membrane polarity, the intracellular $\mathrm{pH}$ and the reorganization of cytoskeleton actin filaments). This capacity was attributed to the rapidly occurring interaction between cell membranes and electro-conductive MWCNTs probably due to the generation of low intensity electrical (ionic) currents occurring in the culture medium exposed to these CNTs [1,2]. CNTs have recently been regarded as interesting candidates for highly selective and permeable solid-state ion channels, mimicking biological ion channels, due to their unique structure. Recent data, 
demonstrating the electrophoretic transport of ions through CNTs [53] support and strengthen our hypothesis that electrochemical interactions, due to the generation of ionic currents, could take place between cell membranes and electro-conductive CNTs. Taken together, our results show, for the first time, that electroconductive MWCNTs can change microglia phenotype and function, without been cytotoxic. These findings could be extremely important in view of the upcoming exploitation of CNTs in nerve tissue engineering since the peculiar effects of some kinds of CNTs on microglia, an important brain cell population that possesses a key role in brain cell network homeostasis and functioning, must be taken into consideration.

\section{Conclusions}

We showed that metallic MWCNTs impact microglia cell phenotype and function and that transition of microglia from M1 to M2 phenotype can be achieved by stimulating cells with CNTs possessing electro-conductive properties. To our knowledge, yet data are lacking on the capabilities of CNTs to modulate microglia function and phenotype without being cytotoxic. Microglia play a key role in the regulation of CNS homeostasis. The dysregulation of the microglial activity is involved in the pathogenesis of neurodegenerative and neuroinflammatory diseases; in these latest, where neuroinflammation is a prominent feature and a potential contributor to the diseases, the alternatively M2 activated microglia would be beneficial in resolving the pathology [28]. Therefore, the potential of a substance to modulate microglial responses could be an attractive therapeutic target, especially in those pathological conditions where classical drugs are ineffective. The intrinsic electrical properties of CNTs should be exploited in a near future to modulate phenotype and functions of these polyhedral brain cells.

\section{Acknowledgements}

The authors thank Federica Andreola for her technical support. This work was partially funded by the Institute of Translational Pharmacology, CNR, Rome, Italy.

\section{Appendix A. Supplementary data}

Supplementary data related to this article can be found at https://doi.org/10.1016/j.carbon.2017.12.069.

\section{References}

[1] S. Fiorito, M. Monthioux, R. Psaila, P. Pierimarchi, M. Zonfrillo, E. D'Emilia, S. Grimaldi, A. Lisi, F. Beguin, R. Almairac, L. Noe, A. Serafino, Evidence for electro-chemical interactions between multi-walled carbon nanotubes and human macrophages, Carbon 47 (12) (2009) 2789-2804.

[2] A. Serafino, A.R. Togna, G.I. Togna, A. Lisi, M. Ledda, S. Grimaldi, J. Russier F. Andreola, M. Monthioux, F. Beguin, M. Marcaccio, S. Rapino, F. Paolucci, S. Fiorito, Highly electroconductive multiwalled carbon nanotubes as potentially useful tools for modulating calcium balancing in biological environments, Nanomed. Nanotechnol. Biol. Med. 8 (3) (2012) 299-307.

[3] A. Fabbro, M. Prato, L. Ballerini, Carbon nanotubes in neuroregeneration and repair, Adv. Drug Deliv. Rev. 65 (15) (2013) 2034-2044.

[4] H. Hu, Y.C. Ni, V. Montana, R.C. Haddon, V. Parpura, Chemically functionalized carbon nanotubes as substrates for neuronal growth, Nano Lett. 4 (3) (2004) $507-511$.

[5] K. Matsumoto, C. Sato, Y. Naka, R.L.D. Whitby, N. Shimizu, Stimulation of neuronal neurite outgrowth using functionalized carbon nanotubes, Nanotechnology 21 (11) (2010).

[6] A. Fabbro, A. Villari, J. Laishram, D. Scaini, F.M. Toma, A. Turco, M. Prato, L. Ballerini, Spinal cord explants use carbon nanotube interfaces to enhance neurite outgrowth and to fortify synaptic inputs, Acs Nano 6 (3) (2012) 2041-2055.

[7] S. Lanone, P. Andujar, A. Kermanizadeh, J. Boczkowski, Determinants of carbon nanotube toxicity, Adv. Drug Deliv. Rev. 65 (15) (2013) 2063-2069.

[8] J.C. Villegas, L. Alvarez-Montes, L. Rodriguez-Fernandez, J. Gonzalez,
R. Valiente, M.L. Fanarraga, Multiwalled carbon nanotubes hinder microglia function interfering with cell migration and phagocytosis, Adv. Healthc Mater. 3 (3) (2014) 424-432.

[9] L.Y. Zhang, D. Alizadeh, B. Badie, Carbon nanotube uptake and toxicity in the brain, Carbon Nanotub.: Meth. Protoc. 625 (2010) 55-65.

[10] K. Bhattacharya, F.T. Andon, R. El-Sayed, B. Fadeel, Mechanisms of carbon nanotube-induced toxicity: focus on pulmonary inflammation, Adv. Drug Deliv. Rev. 65 (15) (2013) 2087-2097.

[11] C. Bussy, K.T. Al-Jamal, J. Boczkowski, S. Lanone, M. Prato, A. Bianco, K. Kostarelos, Microglia determine brain region-specific neurotoxic responses to chemically functionalized carbon nano tubes, Acs Nano 9 (8) (2015) 7815-7830.

[12] O. Vittorio, V. Raffa, A. Cuschieri, Influence of purity and surface oxidation on cytotoxicity of multiwalled carbon nanotubes with human neuroblastoma cells, Nanomater. Nanotechnol. 5 (4) (2009) 424-431.

[13] L. Meng, A.H. Jiang, R. Chen, C.Z. Li, L.M. Wang, Y. Qu, P. Wang, Y.L. Zhao, C.Y. Chen, Inhibitory effects of multiwall carbon nanotubes with high iron impurity on viability and neuronal differentiation in cultured PC12 cells, Toxicology 313 (1) (2013) 49-58.

[14] G. Bardi, A. Nunes, L. Gherardini, K. Bates, K.T. Al-Jamal, C. Gaillard, M. Prato, A. Bianco, T. Pizzorusso, K. Kostarelos, Functionalized carbon nanotubes in the brain: cellular internalization and neuroinflammatory responses, Plos One 8 (11) (2013), e80964.

[15] G. Bardi, P. Tognini, G. Ciofani, V. Raffa, M. Costa, T. Pizzorusso, Pluroniccoated carbon nanotubes do not induce degeneration of cortical neurons in vivo and in vitro, Nanomater. Nanotechnol. 5 (1) (2009) 96-104.

[16] B. Kateb, M. Van Handel, L.Y. Zhang, M.J. Bronikowski, H. Manohara, B. Badie, Internalization of MWCNTs by microglia: possible application in immunotherapy of brain tumors, NeuroImage 37 (2007) S9-S17.

[17] L. Belyanskaya, S. Weigel, C. Hirsch, U. Tobler, H.F. Krug, P. Wick, Effects of carbon nanotubes on primary neurons and glial cells, Neurotoxicology 30 (4) (2009) 702-711

[18] A. Verkhratsky, J.J. Rodriguez, V. Parpura, Astroglia in neurological diseases, Future Neurol. 8 (2) (2013) 149-158.

[19] A. Verkhratsky, M.V. Sofroniew, A. Messing, N.C. Delanerolle, D. Rempe, J.J. Rodriguez, M. Nedergaard, Neurological diseases as primary gliopathies: a reassessment of neurocentrism, Asn Neuro 4 (3) (2012).

[20] W.J. Streit, Microglia as neuroprotective, immunocompetent cells of the CNS, Glia 40 (2) (2002) 133-139.

[21] Y. Tang, W.D. Le, Differential roles of M1 and M2 microglia in neurodegenerative diseases, Mol. Neurobiol. 53 (2) (2016) 1181-1194.

[22] A. Nimmerjahn, F. Kirchhoff, F. Helmchen, Resting microglial cells are highly dynamic surveillants of brain parenchyma in vivo, Science 308 (5726) (2005) $1314-1318$

[23] D. Davalos, J. Grutzendler, G. Yang, J.V. Kim, Y. Zuo, S. Jung, D.R. Littman, M.L. Dustin, W.B. Gan, ATP mediates rapid microglial response to local brain injury in vivo, Nat. Neurosci. 8 (6) (2005) 752-758.

[24] J.L. Marin-Teva, I. Dusart, C. Colin, A. Gervais, N. van Rooijen, M. Mallat Microglia promote the death of developing Purkinje cells, Neuron 41 (4) (2004) 535-547.

[25] S.C. Morgan, D.L. Taylor, J.M. Pocock, Microglia release activators of neurona proliferation mediated by activation of mitogen-activated protein kinase, phosphatidylinositol-3-kinase/Akt and delta-Notch signalling cascades, J. Neurochem. 90 (1) (2004) 89-101.

[26] J. Aarum, K. Sandberg, S.L.B. Haeberlein, M.A.A. Persson, Migration and differentiation of neural precursor cells can be directed by microglia, Proc Natl Acad Sci U S A 100 (26) (2003) 15983-15988.

[27] C.A. Colton, Heterogeneity of microglial activation in the innate immune response in the brain, J. Neuroimmune Pharmacol. 4 (4) (2009) 399-418.

[28] M.W. Salter, S. Beggs, Sublime microglia: expanding roles for the guardians of the CNS, Cell 158 (1) (2014) 15-24.

[29] A.I. Rojo, G. McBean, M. Cindric, J. Egea, M.G. Lopez, P. Rada, N. Zarkovic, A. Cuadrado, Redox control of microglial function: molecular mechanisms and functional significance, Antioxidants Redox Signal. 21 (12) (2014) 1766-1801.

[30] S.M. Robert, T. Ogunrinu-Babarinde, K.T. Holt, H. Sontheimer, Role of glutamate transporters in redox homeostasis of the brain, Neurochem. Int. 73 (2014) 181-191.

[31] G. Pepe, G. Calderazzi, M. De Maglie, A.M. Villa, E. Vegeto, Heterogeneous induction of microglia M2a phenotype by central administration of interleukin-4, J Neuroinflamm 11 (2014).

[32] E. Flahaut, R. Bacsa, A. Peigney, C. Laurent, Gram-scale CCVD synthesis of double-walled carbon nanotubes, Chem. Commun. (12) (2003) 1442-1443.

[33] S. Fiorito, E. Flahaut, S. Rapino, F. Paolucci, F. Andreola, N. Moroni, E. Pittaluga, M. Zonfrillo, G. Valenti, A. Mastrofrancesco, F. Groppi, E. Sabbioni, E. Bakalis, F. Zerbetto, A. Serafino, Redox active Double Wall Carbon Nanotubes show intrinsic anti-proliferative effects and modulate autophagy in cancer cells, Carbon 78 (2014) 589-600.

[34] P. Bonini, S. Cicconi, A. Cardinale, C. Vitale, A.L. Serafino, M.T. Ciotti, L.N. Marlier, Oxidative stress induces p53-mediated apoptosis in glia: p53 transcription-independent way to die, J. Neurosci. Res. 75 (1) (2004) 83-95.

[35] M. Soligo, V. Protto, F. Florenzano, L. Bracci-Laudiero, F. De Benedetti, A. Chiaretti, L. Manni, The mature/pro nerve growth factor ratio is decreased in the brain of diabetic rats: analysis by ELISA methods, Brain Res. 1624 (2015) 455-468.

[36] Y.H. Huang, D.E. Bergles, Glutamate transporters bring competition to the 
synapse, Curr. Opin. Neurobiol. 14 (3) (2004) 346-352.

[37] A. Roy, Y.K. Fung, X. Liu, K. Pahan, Up-regulation of microglial CD11b expression by nitric oxide, J. Biol. Chem. 281 (21) (2006) 14971-14980.

[38] D. Piani, M. Spranger, K. Frei, A. Schaffner, A. Fontana, Macrophage-induced cytotoxicity of N-methyl-D-aspartate receptor positive neurons involves excitatory amino acids rather than reactive oxygen intermediates and cytokines, Eur. J. Immunol. 22 (9) (1992) 2429-2436.

[39] S.W. Barger, A.S. Basile, Activation of microglia by secreted amyloid precursor protein evokes release of glutamate by cystine exchange and attenuates synaptic function, J. Neurochem. 76 (3) (2001) 846-854.

[40] F.K. van Landeghem, J.F. Stover, I. Bechmann, W. Bruck, A. Unterberg, C. Buhrer, A. von Deimling, Early expression of glutamate transporter proteins in ramified microglia after controlled cortical impact injury in the rat, Glia 35 (3) (2001) 167-179.

[41] M. Persson, M. Brantefjord, E. Hansson, L. Ronnback, Lipopolysaccharide increases microglial GLT-1 expression and glutamate uptake capacity in vitro by a mechanism dependent on TNF-alpha, Glia 51 (2) (2005) 111-120.

[42] D. Trotti, N.C. Danbolt, A. Volterra, Glutamate transporters are oxidantvulnerable: a molecular link between oxidative and excitotoxic neurodegeneration? Trends Pharmacol. Sci. 19 (8) (1998) 328-334.

[43] R. Levi-Montalcini, The nerve growth factor 35 years later, Science 237 (4819) (1987) 1154-1162.

[44] G. Prencipe, G. Minnone, R. Strippoli, L. De Pasquale, S. Petrini, I. Caiello, L. Manni, F. De Benedetti, L. Bracci-Laudiero, Nerve growth factor downregulates inflammatory response in human monocytes through TrkA,
J. Immunol. 192 (7) (2014) 3345-3354.

[45] M. Szabo, K. Gulya, Development of the microglial phenotype in culture, Neuroscience 241 (2013) 280-295.

[46] Y. Nakamura, Q.S. Si, K. Kataoka, Lipopolysaccharide-induced microglial activation in culture: temporal profiles of morphological change and release of cytokines and nitric oxide, Neurosci. Res. 35 (2) (1999) 95-100.

[47] W.Y. Tam, C.H. Ma, Bipolar/rod-shaped microglia are proliferating microglia with distinct M1/M2 phenotypes, Sci. Rep. 4 (2014) 7279.

[48] S.E. Taylor, C. Morganti-Kossmann, J. Lifshitz, J.M. Ziebell, Rod microglia: a morphological definition, PloS One 9 (5) (2014), e97096.

[49] D. Boche, V.H. Perry, J.A. Nicoll, Review: activation patterns of microglia and their identification in the human brain, Neuropathol. Appl. Neurobiol. 39 (1) (2013) 3-18.

[50] M.B. Graeber, Changing face of microglia, Science 330 (6005) (2010) 783-788.

[51] T. Wierzba-Bobrowicz, E. Gwiazda, E. Kosno-Kruszewska, E. Lewandowska, W. Lechowicz, E. Bertrand, G.M. Szpak, B. Schmidt-Sidor, Morphological analysis of active microglia-rod and ramified microglia in human brains affected by some neurological diseases (SSPE, Alzheimer's disease and Wilson's disease), Folia Neuropathol. 40 (3) (2002) 125-131.

[52] N.P.B. Au, C.H.E. Ma, Recent advances in the study of bipolar/rod-shaped microglia and their roles in neurodegeneration, Front. Aging Neurosci. 9 (2017) 128.

[53] K. Yazda, S. Tahir, T. Michel, B. Loubet, M. Manghi, J. Bentin, F. Picaud, J. Palmeri, F. Henn, V. Jourdain, Voltage-activated transport of ions through single-walled carbon nanotubes, Nanoscale 9 (33) (2017) 11976-11986. 